УДК 616.127-005.8-085

DOI: $10.26435 /$ UC.V0I1(34).366

\author{
И.С. Греков, М.В. Грушина
}

ГОО ВПО «Донецкий национальный медицинский университет имени М. Горького», Донецк

\title{
ИНФАРКТОПОДОБНЫЕ СОСТОЯНИЯ В КЛИНИЧЕСКОЙ ПРАКТИКЕ ВРАЧА-КАРДИОЛОГА
}

В настоящее время диагностика инфарктов миокарда на догоспитальном и госпитальном этапах не представляет особых трудностей. Повышенный уровень специфических биомаркеров, соответствующие изменения на электрокардиограмме, ангинозная боль в анамнезе все это зачастую указывает на наличие ишемического повреждения сердечной мышцы. Однако существуют патологические состояния, которые по клиническому течению имитируют острый инфаркт миокарда и тем самым могут затруднить диагностику самого инфаркта. Поэтому чрезвычайно важно дифференцировать инфарктоподобные заболевания и истинный инфаркт миокарда, так как подход к терапии и ведение таких пациентов будут принципиально различаться. Чтобы правильно провести дифференциальную диагностику, необходимо знать о целом спектре состояний, сопровождающихся признаками острого инфаркта миокарда. В данной статье мы коснемся лишь тех патологий, которые сходны с проявлением острого инфаркта по всем основным диагностическим критериям и которые наиболее часто вызывают затруднения в диагностическом поиске врача.

\section{Некоторые аспекты диагностики инфаркта миокарда}

Сердечно-сосудистые заболевания - одна из глобальных проблем современного здравоохранения. На сегодняшний день ишемическая болезнь сердца занимает лидирующую позицию по распространенности и заболеваемости среди пациентов с кардиоваскулярной патологией. Несмотря на определенные успехи в лечении инфаркта миокарда как проявления ишемической болезни сердца или ее исхода, смертность в США в 2016 году от данной патологии составила 34,6 на 100 тыс. населения, а в Российской Федерации этот показатель равнялся 42,2 на 100 тыс. населения [1].

Согласно четвертому универсальному определению инфаркта миокарда, термин «инфаркт миокарда» следует использовать при выявлении повреждения сердечной мышцы в сочета- нии с клиническими доказательствами ишемии миокарда [2]. Сам же термин «повреждение миокарда» может быть использован при повышении уровня кардиальных тропонинов выше 99 перцентиля от верхней границы нормы. Здесь также принципиально важно различать эти два понятия, хоть они и не исключают друг друга. В случае истинного инфаркта миокарда происходит повреждение сердечной мышцы вследствие ишемии, во всех остальных случаях следует говорить о повреждении неишемического генеза. Значимость биохимического подхода в диагностике инфарктов трудно переоценить [2, 3]. Раннее выявление специфических маркеров позволяет судить о наличии какого-либо повреждения сердечной мышцы. Предпочтительными маркерами, рекомендованными как для диагностики, так и для исключения повреждений миокарда, а также для установления конкретного подтипа инфаркта, являются сердечные тропонины I и Т. Но уровень этих ферментов может быть значительно повышен и при других состояниях. Ниже приведены основные патологии и состояния, которые сопровождаются увеличением уровня тропонинов $[2,4,5]$ :

- контузия сердца или другие травматические повреждения, включая операции шунтирования, абляции, установка кардиостимулятора и другие

- острая и хроническая сердечная недостаточность;

- перикардиты, миокардиты, эндокардиты;

- гипертрофическая кардиомиопатия;

- кардиомиопатия Токацубо;

- диссекция аорты, заболевания аортальных клапанов;

- эндотелиальная дисфункция без гемодинамически значимых стенозов;

- стеноз коронарных сосудов;

- рабдомиолиз с повреждением миокарда;

(c) И.С. Греков, М.В. Грушина, 2020

(c) Университетская Клиника, 2020 
- эмболия легочной артерии, легочная гипертензия;

- почечная недостаточность;

- тяжелая неврологическая патология, включая инсульт или субарохноидальное кровоизлияние;

- инфильтративные заболевания, такие как амилоидоз, саркоидоз, склеродермия;

- влияние кардиотоксических препаратов;

- критическое состояние, особенно с дыхательной недостаточностью или септическим шоком;

- ожоги, особенно при >30\% повреждении площади тела;

- тяжелый физический труд.

Не следует забывать и о том, что существуют и другие, менее специфические маркеры, имеющие некоторую диагностическую и прогностическую ценность. Это прежде всего КФК-МВ фракция, миоглобин, который имеет высокую специфичность к ткани миокарда, гликогенфосфорилаза, а также белок, связывающий жирные кислоты и легкие цепи миозина. Три последних биомаркера - гликогенфосфорилаза, белок, связывающий жирные кислоты, и легкие цепи миозина - разработаны относительно недавно и не имеют широкого применения в клинике [6].

Среди перечисленных маркеров приоритет в диагностике повреждения миокарда принадлежит именно определению количества фермента КФК-МВ. Несколько иным является профиль вымывания КФК-МВ и тропонинов в периферическую венозную кровь. Так, диагностически значимые концентрации КФК-МВ определяют в среднем на 30-60 мин. раньше, чем у тропонинов, однако гипертропонинемия продолжается приблизительно на неделю дольше повышения КФК-МВ, что, несомненно, очень информативно в случае диагностики острого инфаркта post factum. Повышение уровня миоглобина определяется еще на 60 минут раньше уровня КФК-МВ фракции. Однако, согласно клиническим рекомендациям, в лабораторной диагностике делают акцент именно на количество тропонинов в крови $[2,4,6]$.

Хотя повышенные значения сердечных тропонинов отражают повреждение миокардиальных клеток, они не указывают на основные патофизиологические механизмы, приводящие к этому повреждению. Поэтому здесь наиболее целесообразно сопоставлять биохимические данные с данными других методов диагностики. Одним из таких методов является, несомненно, ЭКГ. Классическими признаками ишемии или изменений вследствие ишемии являются смещение сегмента ST выше или ниже изолинии, изменение зубца Т и наличие или отсутствие патологического зубца Q [4, 6]. Другие изменения ЭКГ, связанные с острой ишемией миокарда, включают нарушения ритма сердца, внутрижелудочковые нарушения проведения по ножкам пучка Гиса, атриовентрикулярные блокады и сниженные амплитуды зубцов R в прекардиальных отведениях - менее специфические находки. В случае изменений на электрокардиограмме сегмента ST его смещение необходимо оценивать относительно комплекса QRS, служащего контрольной точкой в точке J. Точка J - это переход между терминальным зубцом комплекca QRS и началом сегмента ST. У пациентов со стабильной изолинией сегмент ТP (изоэлектрический интервал) является более точным методом оценки величины смещения сегмента ST, что имеет немаловажное значение для дифференциальной диагностики некоторых состояний, имитирующих инфаркт [2, 7].

Однако тахикардия и исходное смещение изолинии достаточно часто затрудняют такую интерпретацию при оценке неотложной ЭКГ. Поэтому начало комплекса QRS рекомендуется брать в качестве контрольной точки для определения смещения точки J [2, 4]. Очень важное значение имеет оценка архива электрокардиограмм, особенно у пациентов с ранее перенесенными инфарктами миокарда. Метод ЭКГ является одним из основных, но его данных недостаточно, чтобы диагностировать ишемическое повреждение, так как многие состояния также имеют подобные изменения, и уж тем более очень сложно предположить патофизиологию повреждения при неишемическом повреждении сердечной мышцы. Ниже приведены состояния, затрудняющие ЭКГ диагностику острого инфаркта миокарда $[4,6]$, при которых наблюдаются сходные с ишемическими изменения на ЭКГ:

ложноположительные

- синдром Бругада;

- синдром ранней реполяризации желудочков;

- перикардит;

- миокардит;

- тромбоэмболия легких;

- субарахноидальное кровоизлияние;

- гипертрофическая и дилатационная кардиомиопатии ;

- кардиромиопатия Такоцубо;

- гипер- или гипокалиемия;

- холецистит;

- прием трициклических антидепрессантов;

- ювенильная электрокардиограмма;

ложноотрицательные

- блокада левой ножки пучка Гиса;

- перенесенный ранее Q-инфаркт миокарда. 
Анамнестические сведения больного и данные физикального обследования также имеют большое дифференциально-диагностическое значение. Наличие ангинозной боли, место ее иррадиации, время и характер ее возникновения вместе с такими признаками, как наличие ишемических эквивалентов (усталость, одышка), профузного потоотделения, страха смерти и т.п., часто наблюдаются у пациентов с острым инфарктом миокарда, однако являются не строго специфичными. Особого внимания требуют пациенты с нетипичной локализацией боли или с наличием немой формы инфаркта.

\section{Диагностические аспекты состояний, затруд-} няющих диагностику инфаркта миокарда

Ниже приведены основные состояния, имитирующие инфаркт миокарда [6, 8].

- миокардит;

- перикардит;

- гипертрофическая кардиомиопатия;

- кардиомиопатия Такоцубо;

- тромбоэмболия легочной артерии;

- диссекция аорты;

- инсульт или субарахноидальное кровоизлияние.

\section{Миокардит}

Некоторые варианты миокардитов по клиническому течению очень сходны с проявлением ишемии миокарда, поэтому дифференциальная диагностика миокардита и инфаркта миокарда бывает весьма затруднительна [9]. Пациенты предъявляют жалобы на боль за грудиной сжимающего характера, которая в 80 \% случаев не купируется приемом нитроглицерина. Характерна также и иррадиация боли в левое плечо, под левую лопатку и в нижнюю челюсть. При регистрации ЭКГ у таких пациентов обнаруживается подъем сегмента ST в грудных отведениях в $54 \%$ случаев, отрицательный зубец Т - в $27 \%$, депрессия сегмента ST - в $18 \%$ случаев, патологический зубец Q - в 27\% случаев. Нередко при миокардитах наблюдается нарушение ритма и проводимости, в том числе и блокада левой ножки пучка Гиса. Параллельно наблюдается повышение сердечных тропонинов Т и I и КФК - МВ фракции [10].

Несмотря на клиническую схожесть такого состояния с инфарктом миокарда, важным дифференциально-диагностическим критерием будет служить анамнез пациента. Четко должна прослеживаться связь заболевания с перенесенными инфекциями, аллергическими реакциями или с токсическими воздействиями. Но наличие инфекции возможно и в качестве сопутствующей патологии, то есть вирусная инфекция не является ведущим, но служит вспомогательным признаком, позволяющим заподозрить отлич- ный от ишемического механизм поражения сердечной мышцы [10]. В дополнение к анамнестическим данным воспалительный генез возможного некротического поражения миокарда может подтвердить диффузная гипокинезия стенок левого желудочка со значительным снижением фракции выброса при ЭхоКГ, однако следует помнить, что данный метод является неспецифичным и его желательно использовать в качестве дополнения к другим методам диагностики. Существенную помощь в диагностике миокардита оказывает радиоизотопная сцинтиграфия с использованием индий-111-оксима и цитрата галлия-67, а также магнитно-резонансная томография с гадолинием, позволяющая установить морфологические признаки воспаления [6, 8, 11]. Магнитно-резонансная томография может рассматриваться как альтернативный метод эндомиокардиальной биопсии, которая в реальной практике используется очень редко [8]. Уровень С-реактивного белка в крови не является специфическим при миокардиальном воспалении, так как наблюдается его корреляция при наличии у пациента острого коронарного синдрома или инфаркта миокарда [6]. Вместо этого показателя следует обращать внимание на наличие иммуноглобулинов класса $\mathrm{G}$ и $\mathrm{M}$ в крови у таких больных, что также может свидетельствовать в пользу воспалительного процесса. Следует всегда помнить, что диагноз острого миокардита требует комплексной оценки анамнестических, клинических и инструментальнолабораторных данных.

\section{Перикардит}

Несмотря на повышение кардиоспецифических маркеров, особенно тропонинов Т и I, их не стоит использовать для дифференциальной диагностики острого инфаркта и острого перикардита [12]. ЭКГ при таком состоянии имеет ряд своих особенностей. При перикардите смещение сегмента ST выше изолинии и инверсия зубца Т регистрируются почти во всех стандартных, однополюсных отведениях от конечностей и в большинстве грудных отведений. При этом отрицательный зубец Т обычно появляется через несколько дней после подъема сегмента ST. Такие изменения на ЭКГ при острых перикардитах формируются и исчезают более медленно по сравнению с острыми инфарктами миокарда [2]. Важным является и появление депрессии сегмента ТР. Также при перикардитах отсутствует патологический зубец Q. При воспалении в предсердии на кардиограмме регистрируются изменения сегмента PR, которые часто могут предшествовать изменениям сегмента ST. B остальном диагностическая концепция при пе- 
рикардитах очень сходна при таковой у пациентов с миокардитом $[2,4]$.

Следует обращать внимание и на некоторые патогномоничные признаки и симптомы, которые будут наблюдаться при разных вариантах перикардита и отсутствовать у больных с инфарктом миокарда: шум трения перикарда, вынужденное положение больного - сидя с наклоном туловища, выбухание грудной клетки в области проекции сердца, ослабление или исчезновение верхушечного толчка и т.п.

\section{Кардиомиопатия Такоцубо и другие карди- омиопатии}

Кардиомиопатия Такоцубо занимает важное место среди сердечно-сосудистых заболеваний. Связано это прежде всего с тем, что в остром периоде по клиническим характеристикам болезнь напоминает острый инфаркт миокарда. Данная патология развивается чаще всего под действием эмоционального или физического стресса, страдает преимущественно женский пол молодого возраста [13]. Клиника проявляется острым началом, характерно наличие загрудинных болей и приступов одышки. Изменения на электрокардиограмме развиваются примерно в 80-85 \% случаев. Характерными ЭКГ признаками при кардиомиопатии Такоцубо являются элевация сегмента ST и инвертированные зубцы Т, при будут отсутствовать реципрокные изменения и подъем сегмента ST в V1 с некоторым удлинением интервала QT (> 500мс). В 25-30 \% случаев развивается патологический зубец Q [14].

Также повышается и уровень сердечных биомаркеров. У пациентов с кардиомиопатией Такоцубо тропонин повышается в 86,2 \% случаев, а уровень МВ-КФК - в 73,9 \% случаев. При этом уровень этих ферментов в несколько раз меньше, чем при инфаркте миокарда. Для более точной диагностики необходимо определить отношение NT-proBNP (мозговой натрийуретический пептид)/Тропонин I . При кардиомиопатии Такоцубо NT-proBNP повышается более значительно, чем при инфаркте миокарда, а тропонин I - незначительно $[14,15]$.

Стандартом в диагностике подобной патологии можно считать ЭхоКГ. При этом на ЭхоКГ будут четко видны зоны акинезии и гипокинезии средних и верхушечных отделов и гиперкинез базальных отделов левого желудочка. Фракция выброса левого желудочка обычно составляет не более 40 \%, при этом через 2-3 недели от манифестации заболевания систолическая функция левого желудочка полностью восстанавливается, чего не наблюдается при инфаркте. При выполнении коронаровентрикулографии можно увидеть классическое апикальное баллоно- образное расширение левого желудочка, которое встречается только при данной патологии. На коронарографии гемодинамически значимых стенозов не наблюдается. Иногда в дифференциальной диагностике применяют такие методы визуализации, как магнитно-резонансную томографию с гадолинием, который при кардиомиопатии Такоцубо не накапливается в отличие от повреждения сердечной мышцы при инфаркте или миокардите [16].

Необходимо также дифференцировать другие виды кардиомиопатий и ишемическое повреждение.

При гипертрофической кардиомиопатии клиника будет проявляться кардиалгией и дискомфортом в грудной клетке в 75\% случаев, классической стенокардией напряжения - в 25 \% случаев. Почти всегда наблюдается одышка при физической нагрузке. Повышение кардиальных ферментов незначительно. На ЭКГ - депрессия сегмента ST и инверсии зубца Т, также в $25 \%$ случаев наблюдаются патологические зубцы Q [6]. Течение такого заболевания медленное, поэтому симптомы носят не острый характер. В диагностике как обструктивной, так и не обструктивной формы данной патологии наиболее информативным остается физикальное обследование и ультразвуковая диагностика.

\section{Тромбоэмболия легочной артерии (ТЭЛА)}

ТЭЛА является самой частой после острого инфаркта миокарда причиной повышения уровня тропонина. Положительные результаты тропониновых тестов были представлены в 1647 \% случаев в нескольких исследованиях, в связи с чем изменение уровня тропонинов предлагают использовать как фактор риска для принятия решения в пользу тромболизиса или эмболэктомии. На электрокардиограмме изменения отражают острую перегрузку правых отделов сердца и легочную гипертензию: наблюдается характерный синдром Мак Джина-Уайта (синдром SI-QIII), появление зубца Q в III отведении, одновременное увеличение амплитуды зубца S в I отведении и отрицательного зубца Т в III отведении, блокада правой ножки пучка Гиса, P-pulmonale, появление отрицательных зубцов Т в отведениях VI-VIII, подъем сегмента ST в отведениях III, aVF, aVR, VI-VIII [17, 18]. Следует отметить, что данные изменения не строго специфичны и у 20-25\% больных с тромбоэмболией изменения на электрокардиограмме вообще могут отсутствовать. Поэтому важной частью дифдиагностики такого состояния является анализ анамнеза пациента. Так, тромбоэмболия обычно развивается в послеоперационном (особенно после абдоминальных, урологических, гинекологических операций) или после- 
родовом периоде, а также у больных тромбофлебитом или флеботромбозом. По сравнению с инфарктом миокарда, где в большинстве случаев кардиальные синдромы превалируют в клинике, при ТЭЛА более характерно острое появление (или нарастание) признаков правожелудочковой недостаточности, чем болевой синдром.

Другим ключевым моментом диагностики при тромбоэмболии являются данные дополнительных методов исследования. Эталонным методом диагностики на сегодняшний день остается ангиопульмонография, которая позволяет получить максимальную информацию об анатомическом и функциональном состоянии пульмональных сосудов. При этом выделяют специфические ангиографические критерии, такие как дефект наполнения в просвете сосуда и/или полная его обструкция. Другая альтернатива ангиопульмонографии - это компьютерная томография с введением рентгеноконтрастного препарата [19].

Метод эхокардиографии также считается наиболее быстрым, удобным и безопасным, позволяющим в кратчайшие сроки получить информацию о влиянии тромбоэмбола на функцию правого желудочка. Однако такой метод имеет целый ряд ограничений, и его роль в диагностике не следует переоценивать.

Также следует правильно интерпретировать данные лабораторной диагностики. Так, помимо увеличения уровня тропонинов, для ТЭЛА характерно увеличение активности лактатдегидрогеназы (ЛДГ), особенно ЛДГ-3, при нормальном содержании КФК-МВ фракции. Также наблюдается повышение BNP или NT-proBNP, но это повышение не является строго специфичным. Наибольшее значение в диагностике ТЭЛА имеет определение D- димера в плазме крови [6, 8].

\section{Диссекция аорты}

По данным основных и дополнительных методов обследования, диагноз расслоения аорты может быть поставлен только у $50 \%$ всех больных.

Клиническая картина обусловлена локализацией процесса расслоения, однако наиболее частым симптомом остается загрудинная боль. Она отличается необычайной интенсивностью и возникает внезапно, с максимальной выраженностью в начале расслоения, в отличие от инфаркта миокарда, где нарастает постепенно. Боль имеет разрывающий, простреливающий характер, может быть мигрирующей от места возникновения, а также сопровождаться вагусными проявлениями. При физикальном исследовании более чем у $55 \%$ больных отмечается асимметрия пульсации и уровня артери- ального давления на верхних и нижних конечностях. При перкуссии отмечается расширение тени средостения. При аускультации может выслушиваться на аортальном клапане как систолический шум, так и диастолический (при наличии аортальной недостаточности). В зависимости от типа и локализации расслоения шумы могут выслушиваться в разных местах по ходу самой аорты [20].

Электрокардиография выявляет неспецифические для такой патологии признаки гипертрофии левого желудочка - депрессию сегмента ST и отрицательный зубец Т. Известно, что у $30 \%$ пациентов ЭКГ остается без изменений [20, 21]. Таким образом, данные ЭКГ необходимо сопоставлять с данными других методов диагностики, так как отсутствие изменений на ЭКГ у больного с выраженной ангинозной болью, при наличии расширения тени восходящей аорты, позволяет предположить диссекцию аорты.

Рентгенография позволяет заподозрить, но не верифицировать такое заболевание. Данные ультразвукового метода исследования и компьютерной томографии более информативны, однако заключительным методом диагностики является аортография [20].

Инсульт и субарахноидальное кровоизлияние

Несмотря на превалирующую симптоматику острого нарушения мозгового кровообращения, при снятии электрокардиографических показателей может понадобиться исключение острого инфаркта миокарда. Наиболее часто очаговые изменения на ЭКГ наблюдаются в виде инверсии зубца Т у пациентов старше 50 лет. В некоторых исследованиях также сообщалось, что при субарахноидальном кровоизлиянии или инсульте маркеры повреждения миокарда повышаются в 20-40 \% случаев [22]. Однако такое повышение незначительно, и время нахождения в крови таких маркеров также невелико. Поэтому уровень тропонинов чаще используют как прогностический маркер у таких пациентов, а дифференциацию острого инфаркта проводят, опираясь на данные анамнеза и ЭхоКГ [23].

\section{З А К ЛЮ Ч Е Н ИЕ}

Следует всегда помнить, что ангинозная боль, одышка, изменение уровня кардиомаркеров с изменением на электрокардиограмме в виде элевации или депрессии сегмента ST, изменение зубца Т и появление зубца $Q$ не всегда свидетельствуют в пользу наличия ишемического повреждения миокарда, а могут указывать на наличие патологии совсем иного характера. Таким образом, в диагностике инфарктов миокарда необходимо соблюдать комплексный подход, с ис- 
пользованием основных и дополнительных методов диагностики, и правильно интерпретировать полученные данные, чтобы своевременно провести дифференциальную диагностику та- ких инфарктоподобных состояний от истинного инфаркта миокарда, что в свою очередь позволит значительно снизить смертность и возникновение осложнений на госпитальном этапе.

\section{И.С. Греков, М.В. Грушина}

ГОО ВПО «Донецкий национальный медицинский университет имени М. Горького», Донецк

\section{ИНФАРКТОПОДОБНЫЕ СОСТОЯНИЯ В КЛИНИЧЕСКОЙ ПРАКТИКЕ ВРАЧА-КАРДИОЛОГА}

Зачастую постановка диагноза «острый инфаркт миокарда» не представляет особых трудностей. Наличие характерной клинической картины, соответствующих изменений на электрокардиограмме и изменений профиля тропонинов позволяет говорить о вероятном ишемическом повреждении и развитии некроза сердечной мышцы. Однако существуют патологические состояния, которые схожи с инфарктом миокарда по всем диагностическим критериям и тем самым затрудняют диагностику самого инфаркта. В данной обзорной статье описаны инфарктоподобные состо- яния, с которыми наиболее часто приходится проводить дифференциальную диагностику. В статье уделено внимание ключевым признакам, а также основным методам диагностики, позволяющим своевременно дифференцировать истинный инфаркт миокарда и такое инфарктоподобное состояние, что в свою очередь позволит значительно снизить смертность и возникновение осложнений от данной патологии.

Ключевые слова: инфаркт миокарда, инфарктоподобные состояния, сердечные биомаркеры, тропонины.

\section{I.S. Grekov, M.V. Grushina}

\section{SEI HPE «M. Gorky Donetsk National Medical University», Donetsk}

\section{INFARCT-LIKE CONDITIONS IN A CARDIOLOGIST'S CLINICAL PRACTICE}

Often, the diagnosis of "acute myocardial infarction" is not particularly difficult. The presence of a characteristic clinical picture, corresponding changes in the electrocardiogram and changes in the troponins profile allow us to talk about a possible ischemic damage and the development of cardiac muscle necrosis. However, there are pathological conditions that are similar to myocardial infarction in all diagnostic criteria and thus make it difficult to diagnose the infarction itself. This review article describes infarct-like conditions, which most often have to carry out differential diagnosis. The article focuses on the key features, as well as the main diagnostic methods that allow timely differentiation of true myocardial infarction from such infarct-like state, which in turn will significantly reduce mortality and the occurrence of complications from this pathology.

Key words: myocardial infarction, infarct-like conditions, cardiac biomarkers, troponins.

\section{ЛИТЕРАТУРА}

1. Герасимов А.А. Эпидемиологические аспекты инфаркта миокарда в Российской Федерации: Дис. канд.мед. наук. Москва 2019: 85-88.

2. Thygessen K., Alpert J.S., Jaffe A.S. et al. Fourth joint ACC/ AHA/WHF universal definition of myocardial infarction Eur. Heart. J. 2018; 10:1-33.

3. Reichlin T., Hochholzer W., Bassetti S., et al. Early diagnosis of myocardial infarction with sensitive cardiac troponin assays. N. Engl. J. Med. 2009; 361(9):858-867.

4. Thygesen K., Alpert J.S., Jaffe A.S., Simoons M.L., Chaitman B.R., White H.D.; Writing Group on the Joint ESC/ ACC/AHA/WHF Task Force for the Universal Definition of Myocardial Infarction. Third universal definition of myocardial infarction. Eur. Heart. J. 2012; 33: 2551-2567;

5. Воловченко А.Н., Гиляров М.Ю., Сыркин А.Л. Причины повышения уровня тропонина, не связанные с острым коронарным синдромом и сердечной недостаточностью. Кардиология и сердечно-сосудистая хирургия 2012, 3: 18-25.

6. Руководство по кардиологии. Под ред. В.Н. Коваленко.

\section{REFERENCES}

1. Gerasimov A.A. Jepidemiologicheskie aspekty infarkta miokarda v Rossijskoj Federacii: Dis. kand.med.nauk. Moskva 2019: 85-88 (in Russian).

2. Thygessen K., Alpert J.S., Jaffe A.S. et al. Fourth joint ACC/ AHA/WHF universal definition of myocardial infarction Eur. Heart. J. 2018; 10:1-33.

3. Reichlin T., Hochholzer W., Bassetti S., et al. Early diagnosis of myocardial infarction with sensitive cardiac troponin assays. N. Engl. J. Med. 2009; 361(9):858-867.

4. Thygesen K., Alpert J.S., Jaffe A.S., Simoons M.L., Chaitman B.R., White H.D.; Writing Group on the Joint ESC/ ACC/AHA/WHF Task Force for the Universal Definition of Myocardial Infarction. Third universal definition of myocardial infarction. Eur. Heart. J. 2012; 33: 2551-2567;

5. Volovchenko A.N., Giljarov M.Ju., Syrkin A.L. Prichiny povyshenija urovnja troponina, ne svjazannye s ostrym koronarnym sindromom i serdechnoj nedostatochnost'ju. Kardiologija i serdechno-sosudistaja hirurgija 2012, 3: 1825 (in Russian).

6. Rukovodstvo po kardiologii. Pod red. V.N. Kovalenko. - K.: 
- К.: Издательство Морион, 2008: 523-705.

7. Scirica B.M., Morrow D.A., Budaj A., Dalby A.J., Mohanavelu S., Qin J., Aroesty J., Hedgepeth C.M., Stone P.H., Braunwald E. Ischemia detected on continuous electrocardiography after acute coronary syndrome. J Am Coll Cardiol 2009; 53: 1411-1421.

8. Якушин С.С. Инфаркт миокарда с необструктивным поражением коронарных артерий (MINOCA) - модный термин или новая диагностическая концепция? Рациональная Фармакотерапия в Кардиологии 2018; 14(5): 765-773.

9. Гайфуллина Р.Ф., Ким З.Ф., Амиров Н.Б. и др. Инфарктоподобный миокардит: трудности и пути решения в диагностике Вестник современной клинической медицины. 2018. Т. 11; 1: 23-29.

10. Lauer B., Niederau C., Kuehl U. et al. Cardiac troponin T in patients with clinically suspected myocarditis. J Am Coll Cardiol 1997; 30: 1354-1359.

11. Lurz P., Luecke C., Eitel I. et al. Comprehensive Cardiac Magnetic Resonance Imaging in Patients With Suspected Myocarditis: The MyoRacer-Trial J. Am. Coll. Cardiol. 2016; 67 (15): 1800-1811.

12. Imazio M., Demichelis B., Cecchi E. et al. Cardiac troponin I in acute pericarditis. J. Amer. Coll. Cardiol., 2003; 42: 2144-2147.

13. Sharkey S.W., Lesser J.R., Zenovich A.G. et al. Acute and reversible cardiomyopathy provoked by stress in women from the United States. Circulation. 2005; 111 (4): 472 479 .

14. Лебедева А.М., Васильева Е.Ю., Шпектор А.В. Кардиомиопатия такотсубо. Креативная кардиология, 2013; 1. 82-85.

15. Etgen T., Baum H., Sander K., Sander D.. Cardiac troponins and NT-pro-brain natriuretic peptide in acute ischemic stroke do not relate to clinical prognosis. Stroke. 2005; 36(2): 270-275.

16. Prasad A. Apical ballooning syndrome: an important differential diagnosis of acute myocardial infarction. Circulation. $2007 ; 115$ (5): 56-9.

17. Mehta N.J., Jani K., Khan I.A. Clinical usefulness and prognostic value of elevated cardiac troponin I levels in acute pulmonary embolism. Am. Heart. J. 2003; 145(5):821-825.

18. Task Force Report Guidelines on diagnosis and management of acute pulmonary embolism. European Society of Cardiology. Europ. Heart J., 2000; 21: 1301-1336.

19. Greenspan R.H. Pulmonary angiography and the diagnosis of pulmonary embolism. Prog. cardiovasc. dis, 1994; 37, 2: 93-106.

20. Бураковский В.И., Бокерия Л.А. Сердечно-сосудистая хирургия. Руководство. Москва «Медицина», 1989. 656662.

21. ESC Guidelines on the diagnosis and treatment of aortic diseases Document covering acute and chronic aortic diseases of the thoracic and abdominal aorta of the adult. The Task Force for the Diagnosis and Treatment of Aortic Diseases of the European Society of Cardiology (ESC). 2014; 5-50.

22. Naidech A.M., Kreiter K., Janjua N., et al. Cardiac troponin elevation, cardiovascular morbidity and outcome after subarachnoid hemorrhage. Circulation. 2005; 112(18): 2851-2855.

23. Tung P., Kopelnik A., Banki N. Predictors of neurocardiogenic injury after subarachnoid hemorrhage. Stroke. 2004; 35(2): 548-552.
Izdatel'stvo Morion, 2008: 523-705 (in Russian).

7. Scirica B.M., Morrow D.A., Budaj A., Dalby A.J., Mohanavelu S., Qin J., Aroesty J., Hedgepeth C.M., Stone P.H., Braunwald $\mathrm{E}$. Ischemia detected on continuous electrocardiography after acute coronary syndrome. J Am Coll Cardiol 2009; 53: 1411-1421.

8. Jakushin S.S. Infarkt miokarda s neobstruktivnym porazheniem koronarnyh arterij (MINOSA) - modnyj termin ili novaja diagnosticheskaja koncepcija? Racional'naja Farmakoterapija v Kardiologii 2018; 14(5): 765-773 (in Russian).

9. Gajfullina R.F., Kim Z.F., Amirov N.B. i dr. Infarktopodobnyj miokardit: trudnosti i puti reshenija $\mathrm{v}$ diagnostike Vestnik sovremennoj klinicheskoj mediciny. 2018. T. 11; 1: 23-29 (in Russian).

10. Lauer B., Niederau C., Kuehl U. et al. Cardiac troponin T in patients with clinically suspected myocarditis. J Am Coll Cardiol 1997; 30: 1354-1359.

11. Lurz P., Luecke C., Eitel I. et al. Comprehensive Cardiac Magnetic Resonance Imaging in Patients With Suspected Myocarditis: The MyoRacer-Trial J. Am. Coll. Cardiol. 2016; 67 (15): 1800-1811.

12. Imazio M., Demichelis B., Cecchi E. et al. Cardiac troponin I in acute pericarditis. J. Amer. Coll. Cardiol., 2003; 42: 2144-2147.

13. Sharkey S.W., Lesser J.R., Zenovich A.G. et al. Acute and reversible cardiomyopathy provoked by stress in women from the United States. Circulation. 2005; 111 (4): 472 479.

14. Lebedeva A.M., Vasil'eva E.Ju., Shpektor A.V. Kardiomiopatija takotsubo. Kreativnaja kardiologija, 2013; 1. 82-85 (in Russian).

15. Etgen T., Baum H., Sander K., Sander D.. Cardiac troponins and NT-pro-brain natriuretic peptide in acute ischemic stroke do not relate to clinical prognosis. Stroke. 2005; 36(2): 270-275.

16. Prasad A. Apical ballooning syndrome: an important differential diagnosis of acute myocardial infarction. Circulation. 2007; 115 (5): 56-9.

17. Mehta N.J., Jani K., Khan I.A. Clinical usefulness and prognostic value of elevated cardiac troponin I levels in acute pulmonary embolism. Am. Heart. J. 2003; 145(5):821-825.

18. Task Force Report Guidelines on diagnosis and management of acute pulmonary embolism. European Society of Cardiology. Europ. Heart J., 2000; 21: 1301-1336.

19. Greenspan R.H. Pulmonary angiography and the diagnosis of pulmonary embolism. Prog. cardiovasc. dis, 1994; 37, 2: 93-106.

20. Burakovskij V.I., Bokerija L.A. Serdechno-sosudistaja hirurgija. Rukovodstvo. Moskva «Medicina», 1989. 656662 (in Russian).

21. ESC Guidelines on the diagnosis and treatment of aortic diseases Document covering acute and chronic aortic diseases of the thoracic and abdominal aorta of the adult. The Task Force for the Diagnosis and Treatment of Aortic Diseases of the European Society of Cardiology (ESC). 2014; 5-50.

22. Naidech A.M., Kreiter K., Janjua N., et al. Cardiac troponin elevation, cardiovascular morbidity and outcome after subarachnoid hemorrhage. Circulation. 2005; 112(18): 2851-2855.

23. Tung P., Kopelnik A., Banki N. Predictors of neurocardiogenic injury after subarachnoid hemorrhage. Stroke. 2004; 35(2): 548-552. 